\title{
Microbial population analysis of nutrient removal-related organisms in membrane bioreactors
}

\author{
Ana F. Silva • Gilda Carvalho • Adrian Oehmen • \\ Maria Lousada-Ferreira • Arjen van Nieuwenhuijzen • \\ Maria A. M. Reis • M. Teresa Barreto Crespo
}

Received: 17 May 2011 /Revised: 5 July 2011 /Accepted: 18 July 2011 /Published online: 9 August 2011

(C) Springer-Verlag 2011

\begin{abstract}
Membrane bioreactors (MBR) are an important and increasingly implemented wastewater treatment technology, which are operated at low food to microorganism ratios $(\mathrm{F} / \mathrm{M})$ and retain slow-growing organisms. Enhanced biological phosphorus removal (EBPR)-related organisms grow slower than ordinary heterotrophs, but have never been studied in detail in MBRs. This study presents a comprehensive analysis of the microorganisms involved in EBPR in pilot- and full-scale MBRs, using fluorescence in situ hybridization (FISH), as well as an overall assessment
\end{abstract}

Electronic supplementary material The online version of this article (doi:10.1007/s00253-011-3499-5) contains supplementary material, which is available to authorized users.

A. F. Silva $\cdot$ G. Carvalho $(\bowtie) \cdot$ M. T. B. Crespo

Microbiology Laboratory, Instituto de Biologia Experimental e

Tecnológica (IBET),

Av. República, Qta. do Marquês,

2780-157 Oeiras, Portugal

e-mail: gildacarvalho@dq.fct.unl.pt

A. F. Silva $\cdot$ M. T. B. Crespo

Instituto de Tecnologia Química e Biológica (ITQB),

Universidade Nova de Lisboa (UNL),

Qta do Marquês,

2780-157 Oeiras, Portugal

G. Carvalho $\cdot$ A. Oehmen · M. A. M. Reis

REQUIMTE/CQFB, Departamento de Química, Faculdade de

Ciências e Tecnologia, Universidade Nova de Lisboa,

2829-516 Caparica, Portugal

M. Lousada-Ferreira $\cdot$ A. van Nieuwenhuijzen

Department of Water Management, University of Technology,

Stevinweg 1,

2628 CN Delft, The Netherlands

A. van Nieuwenhuijzen

Witteveen Bos Consulting Engn,

7400 AE Deventer, Netherlands of other relevant microbial groups. The results showed that polyphosphate accumulating organisms (PAOs) were present at similar levels in all studied MBRs $(10 \% \pm 6 \%)$, even those without a defined anaerobic zone. Glycogen accumulating organisms were also detected, although rarely. The FISH results correlated well with the observed $\mathrm{P}$ removal performance of each plant. The results from this study suggest that a defined anaerobic zone is not necessarily required for putative PAO growth in MBRs, since polyphosphate storage may provide a selective advantage in fulfilling cell maintenance requirements in substrate-limited conditions (low F/M).

Keywords Membrane bioreactor (MBR) - Biological nutrient removal (BNR) - Fluorescence in situ hybridization (FISH) - Polyphosphate accumulating organisms (PAO) . Glycogen accumulating organisms (GAO)

\section{Introduction}

Membrane bioreactors (MBR) are an increasingly important technology for the treatment of wastewater (Judd 2008). The presence of a membrane that completely retains the solids of the mixed liquor obviates the presence of secondary settlers in a conventional activated sludge (CAS) wastewater treatment plant (WWTP). Thus, MBRs lead to a reduced footprint and high effluent quality (Le-Clech 2010).

The microbial composition of MBRs is still largely unknown, and the presence of a membrane and other specific MBR operational conditions are new selective pressures for the microbial community as compared to CAS systems. The total retention of solids in MBRs implies that all microorganisms are retained in the 
biological tank (except for the biomass purged), as opposed to CAS, where the microbial populations with lower settling capacity are washed out from the clarifiers (Le-Clech 2010).

A few studies have compared the microbial community between MBR and CAS operated in parallel, and all revealed significant differences between the overall community structures (Luxmy et al. 2000; Hall et al. 2010; Wan et al. 2011). MBRs seem to select a more stable microbial community as compared to CAS systems, where higher dynamics were observed (Hall et al. 2010; Wan et al. 2011). Moreover, a large set of novel and uncultured bacterial sequences have been found in an MBR (Wan et al. 2011), which reflects the lack of knowledge concerning MBR microbial populations.

Previous studies have investigated biological nutrient removal (BNR) in MBRs, mainly focusing on the nitrification processes and the populations involved. The same groups of nitrifiers have generally been found in MBRs and CAS. Others groups of bacteria involved in BNR have been very scarcely characterized in MBR systems, such as polyphosphate accumulating organisms (PAOs). PAOs store $\mathrm{P}$ in the form of intracellular polyphosphate granules, which is typically achieved by recirculating the activated sludge between anaerobic and aerobic conditions, a process known as enhanced biological phosphorus removal (EBPR). EBPR is a well-accepted process but prone to failure. Glycogen accumulating organisms (GAOs) grow under the same conditions as PAOs and compete with them for anaerobic uptake of carbon sources, but do not remove phosphorus from the wastewater (Oehmen et al. 2007; Seviour and McIlroy 2008).

Other EBPR studies on MBRs have mainly focused on the optimization of operational conditions for P removal, using chemical analysis to assess the activity of PAOs (Lesjean et al. 2005; Parco et al. 2007; Monclus et al. 2010). In MBRs, to the best of our knowledge, only Fu et al. (2009) have studied the presence, though not the abundance, of one type of PAO (Accumulibacter) in an anoxic/oxic pilot-scale MBR. The abundance of Accumulibacter and other microorganisms relevant in EBPR processes, such as other PAO microbial groups (i.e., Tetrasphaera-related and Dechloromonas-related) and GAOs (i.e., Competibacter and Defluviicoccus-related), have not previously been studied.

Although PAOs thrive under anaerobic/aerobic conditions, they do not necessarily require these operational conditions in order to survive, persisting in bioreactors operated under strict aerobic conditions as well as other aquatic habitats (Pijuan et al. 2006; Peterson et al. 2008). MBRs present a potentially suitable environment for PAO proliferation. PAOs grow slower than ordinary heterotrophic organisms (Smolders et al. 1994), thus being favored in MBRs due to complete biomass retention (Hall et al. 2010). Additionally, the high biomass concentrations normally found in MBRs might lead to areas of anaerobic micro-niches within the sludge flocs in poorly mixed zones, potentially providing PAOs a selective advantage. Nevertheless, the presence of putative PAOs alone does not necessarily imply EBPR activity, which will depend on the operational conditions. Linking the microbial population with the BNR performance achieved in MBRs was the motivation for the present study.

This study characterized the microbial diversity of the activated sludge in a group of eight MBR plants fed with municipal wastewater, located in different regions of Europe. Particular emphasis was given to the populations involved in phosphorus removal, in view of the lack of information about the presence of EBPR-related organisms in MBRs. The abundance of putative PAOs and GAOs was determined through a large set of previously designed probes targeting these microorganisms, and related to the $\mathrm{P}$ removal observed in each plant. This information can contribute to a better understanding of the potential of MBRs to achieve biological $P$ removal.

\section{Materials and methods}

\section{MBR plants}

Eight MBR plants fed with real wastewater were studied. In all plants, the membrane was submerged in a separate tank from the main biological tank(s). Four MBRs were pilotscale systems and four were full-scale plants (see plant locations in Table 1). MBR5 had two flat sheet-type membrane modules with different pore sizes in the membrane tank and MBR7 contained three parallel membrane tanks with different types of membranes. MBR4 and MBR5 were the only two plants specifically designed for EBPR with well-defined anaerobic zones. Details about the design of the MBRs are given in Table 1.

\section{Collection of biomass samples and operational data}

Biomass samples were collected from the membrane tanks and fixed with $4 \%$ paraformaldehyde for Gram-negative bacteria or with ethanol for Gram-positive bacteria (Amann 1995). The corresponding operational parameters and nutrient removal data are shown in Table 2. It should be noted that MBR1 and MBR2 apply chemical precipitation, thus the P removal in these systems was not only attributable to biological activity. 
Table 1 MBR design data

\begin{tabular}{|c|c|c|c|c|c|c|c|c|c|c|}
\hline MBR plant & Location & Scale & Design & $\begin{array}{l}\text { Biological } \\
\text { tanks }\left(\mathrm{m}^{3}\right)\end{array}$ & $\begin{array}{l}\text { Membrane } \\
\operatorname{tank}\left(\mathrm{m}^{3}\right)\end{array}$ & Membrane type & $\begin{array}{l}\text { Total } \\
\text { membrane } \\
\text { area }\left(\mathrm{m}^{2}\right)\end{array}$ & $\begin{array}{l}\text { Membrane } \\
\text { pore size }(\mu \mathrm{m})\end{array}$ & $\begin{array}{l}\mathrm{SAD}_{\mathrm{p}} \\
\left(\mathrm{m}^{3} / \mathrm{m}^{3}\right)\end{array}$ & $\begin{array}{l}\text { Recirculation } \\
\text { ratio }^{\mathrm{a}}\end{array}$ \\
\hline MBR 1 & $\begin{array}{l}\text { Monheim, } \\
\text { Germany }\end{array}$ & Full & Non-EBPR & $\begin{array}{l}680 \text { (aerobic) } \\
680 \text { (anoxic) }\end{array}$ & 300 & $\begin{array}{l}\text { HF (Zenon Ze } \\
\text { eWeed 500c) }\end{array}$ & 12,320 & 0.04 & $12.5-36$ & $11-53$ \\
\hline MBR 2 & $\begin{array}{r}\text { Nordkanal, } \\
\text { Germany }\end{array}$ & Full & Non-EBPR & $\begin{array}{l}\text { 2,609 (anoxic) } \\
916 \text { (aerobic/ } \\
\text { anoxic) }\end{array}$ & 5,784 & $\begin{array}{l}\text { HF (Zenon Zee } \\
\text { Weed 500c) }\end{array}$ & 84,480 & 0.04 & 17 & 4 \\
\hline MBR 3 & Schilde, Belgium & Full & Non-EBPR & $\begin{array}{l}500 \text { (anoxic) } \\
500 \text { (aerobic) }\end{array}$ & 240 & $\begin{array}{l}\text { HF (Zenon Zee } \\
\text { Weed 500c) }\end{array}$ & 10,560 & 0.04 & $10-17.2$ & 5.8 \\
\hline MBR 4 & $\begin{array}{l}\text { Heenvliet, The } \\
\text { Netherlands }\end{array}$ & Full & EBPR & 391 (total) & 152 & FS (Toray) & 4,110 & 0.08 & 12.3 & 2 \\
\hline MBR 5 & $\begin{array}{l}\text { Margarethenhöhe, } \\
\text { Germany }\end{array}$ & Pilot & EBPR & $\begin{array}{l}0.6 \text { (anaerobic) } \\
4 \text { (aerobic) } \\
4 \text { (anoxic) }\end{array}$ & 0.6 & $\begin{array}{l}\text { FS (Martin } \\
\text { Systems } \\
\text { and A3) }\end{array}$ & 69 & $\begin{array}{l}0.035 \text { (Martin } \\
\text { Systems); } \\
0.2 \text { (A3) }\end{array}$ & 20.5 & 4 \\
\hline MBR 6 & Trondheim, Norway & Pilot & Non-EBPR & $\begin{array}{l}0.063 \text { (each } \\
\text { of } 4 \text { tanks) }\end{array}$ & 0.033 & $\begin{array}{l}\text { HF (Zenon Zee } \\
\text { Weed 500c) }\end{array}$ & 3.72 & 0.04 & 18.7 & n.a. \\
\hline MBR 7 & $\begin{array}{l}\text { Zurich, } \\
\text { Switzerland }\end{array}$ & Pilot & Non-EBPR & $\begin{array}{l}0.5 \text { and } 4 \\
\text { (aerobic } \\
\text { tanks) }\end{array}$ & $\begin{array}{l}1.6 \text { (Zenon); } \\
1.4 \text { (Kubota); } \\
0.6 \text { (Puron) }\end{array}$ & $\begin{array}{l}\text { HF (Zenon); FS } \\
\text { (Kubota); HF } \\
\text { (Puron) }\end{array}$ & 116 & 0.04 & $22-73$ & n.a. \\
\hline MBR 8 & Lavis, Italy & Pilot & Non-EBPR & $\begin{array}{l}5 \text { (anoxic) } \\
9.2 \text { (aerobic) }\end{array}$ & 1.5 & $\begin{array}{l}\text { HF (Zenon Zee } \\
\text { Weed 500c) }\end{array}$ & 70 & 0.04 & $17-20$ & 4 \\
\hline
\end{tabular}

$H F$ hollow fiber, $F S$ flat sheet, $S A D_{p}$ specific aeration demand per permeate flow, n.a. not available

${ }^{a}$ Recirculation between the membrane and biological tanks

Microbial community characterization by FISH analysis

Fluorescence in situ hybridization (FISH) analysis was conducted according to Amann (1995). The oligonucleotide probes used are listed in Table 3. Several probes were applied together or sequentially: PAO462, PAO651, and PAO846 (PAOmix); EUB338, EUB338-II, and EUB338-III (EUBmix); GB-G2 and GAOQ989 (GAOmix); TFO_DF218 and TFO_DF618 (TFOmix); DEF988 and DEF1020 (DEFmix); Actino221 and Actino658; and NSO1225 and NSO190. The general probes for Bacteria (EUBmix) were used together with the specific probes for microbial population characterization and quantification purposes. Archaea were visualized against 4',6-diamidino2-phenylindole. The $5^{\prime}$ labeling of EUBmix was either fluorescein isothiocyanate (epifluorescence microscopy) or cyanine 5 (confocal microscopy), while the specific probes were Cy3-labeled. Unless otherwise specified, the probe details can be found in Nielsen et al. (2009).

Semiquantification of Archaea and general bacterial groups commonly present in WWTP (Alpha-, Beta-, and Gammaproteobacteria and Actinobacteria), as well as ammonia-oxidizing bacteria (AOB) and nitrite-oxidizing bacteria (NOB), was carried out using a Leica DMRA2 epifluorescence microscope. A preliminary semiquantification of the PAO and GAO populations was also performed. The EBPR-related populations showing $>1 \%$ of apparent abundance were then quantified using a ZEISS LSM510/ META confocal laser scanning microscope (CLSM) through the analysis of at least 30 images with the softwares Zeiss LSM Image Browser and ImageJ. Quantification values are given as biovolume abundance with respect to the EUBmix signal. The standard error of the mean $\left(\mathrm{SE}_{\text {mean }}\right)$ was calculated as the standard deviation divided by the square root of the number of images.

\section{Results}

General microbial characterization

The epifluorescence microscopic analysis revealed common features in all MBRs studied: the diversity of cellular morphology was high, and many different cell types could be found dispersed in the flocs or grouped in clusters with different sizes and shapes. Filamentous bacteria (of particularly large size in MBR 7, see Fig. S1) were the backbone of the flocs, together with an abundant autofluorescent matrix, likely composed of extracellular polymeric substances (EPS).

In all of the MBRs, the dominant bacteria group was the Betaproteobacteria, followed by the Gammaproteobacteria. Actinobacteria (high $\mathrm{G}+\mathrm{C}$ content Gram-positive bacteria) were also observed in all plants, usually in higher 


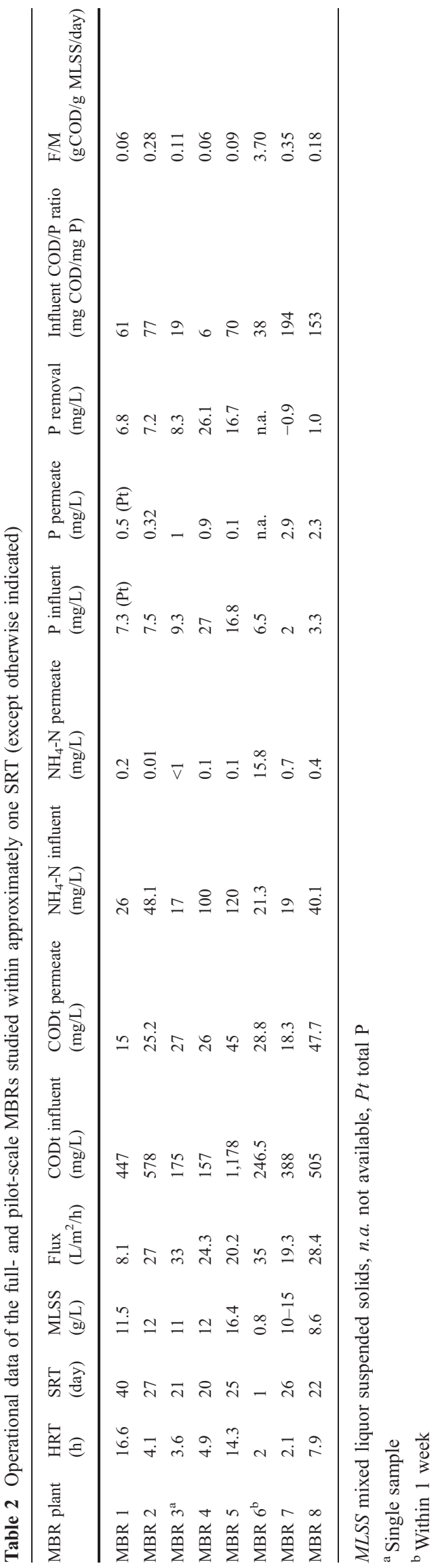

abundance than the Alphaproteobacteria (Table 4). Overall, the general community characteristics in the studied plants were similar to previously reported studies on MBRs, with Betaproteobacteria as the most abundant group (Luxmy et al. 2000; Witzig et al. 2002; Sofia et al. 2004), followed by Gammaproteobacteria (Sofia et al. 2004). Archaea were detected in all of the MBRs except in MBRs 5 and 7, but in low abundance.

Ammonia-oxidizing bacteria and nitrite-oxidizing bacteria characterization

Ammonia-oxidizing Betaproteobacteria were observed through FISH in all MBRs with a low relative abundance, except MBRs 5 and 6, where they were not detected (Table 4). Low or non-detection of AOB fluorescence signal was previously reported for MBR biomass (Luxmy et al. 2000; Witzig et al. 2002; Pala et al. 2008). AOBs were present in the form of small coccobacilli and always grouped in small-sized clusters, although in MBR 3 it was also possible to observe some big AOB cocci dispersed in the flocs. Manser et al. (2005) also reported the small size of $\mathrm{AOB}$ clusters in MBR, possibly related with the high shear forces imposed for membrane scouring. Regarding NOBs, none were detected in MBRs 2, 5, and 6 (Table 4). Nitrobacter sp. was not identified in any MBR samples, which is consistent with previous findings (Wagner and Loy 2002; Kraume et al. 2005; Li et al. 2005; Manser et al. 2005), although Luxmy et al. (2000) reported bright signal detection with the NIT3 FISH probe. The only NOB cells detected in this study belonged to the genus Nitrospira, described in the literature as an active contributor to nitrite oxidation (Kraume et al. 2005; Li et al. 2005; Manser et al. 2005; Nielsen et al. 2009). Nitrospira generally presented cocci morphology, mostly aggregating in small clusters, though in the case of MBR 4, a rod morphology was also observed.

\section{PAO and GAO characterization}

Through applying a comprehensive set of probes targeting the PAO and GAO groups, it was demonstrated that PAOs were present in relatively higher abundance as compared to GAOs (Fig. 1). Accumulibacter (PAOmix), presenting the commonly described morphologies (Carvalho et al. 2007; Oehmen et al. 2007), was absent in MBR 1, but was detected in the remaining systems (Fig. 2). Nevertheless, Accumulibacter was only abundant in MBRs 3 and 5, where it accounted for $10.8 \%\left(\mathrm{SE}_{\text {mean }}=0.5 \%\right)$ and $6.1 \%$ $\left(\mathrm{SE}_{\text {mean }}=0.4 \%\right)$ of the bacterial population, respectively. In the remaining MBRs, Accumulibacter was present in smaller abundance as compared to the Tetrasphaera-PAOs $($ Actino $221+658)$ and/or the Dechloromonas-PAOs 
Table 3 Oligonucleotide FISH probes sequences and target sites

\begin{tabular}{|c|c|c|c|}
\hline & Probe & Sequence $\left(5^{\prime}-3^{\prime}\right)$ & Target \\
\hline \multirow{8}{*}{$\begin{array}{l}\text { Higher taxonomic } \\
\text { levels }\end{array}$} & EUB338 & GCTGCCTCCCGTAGGAGT & Most bacteria \\
\hline & EUB338-III & GCAGCCACCCGTAGGTGT & $\begin{array}{l}\text { Planctomycetales and other bacteria not detected by } \\
\text { EUB338 }\end{array}$ \\
\hline & EUB338-II & GCTGCCACCCGTAGGTGT & $\begin{array}{l}\text { Verrucomicrobiales and other bacteria not detected by } \\
\text { EUB } 338\end{array}$ \\
\hline & ALF969 $9^{a}$ & TGGTAAGGTTCTGCGCGT & Alphaproteobacteria \\
\hline & BET42a & GCCTTCCCACTTCGTTT & Betaproteobacteria \\
\hline & GAM42a & GCCTTCCCACATCGTTT & Gammaproteobacteria \\
\hline & HGC69a & TATAGTTACCACCGCCGT & High $\mathrm{G}+\mathrm{C}$ content Gram-positive bacteria (Actinobacteria) \\
\hline & $\operatorname{Arc} 915^{\mathrm{b}}$ & GTGCTCCCCCGCCAATTCCT & Archaea \\
\hline \multirow[t]{8}{*}{ PAO } & PAO462 & CCGTCATCTACWCAGGGTATTAAC & Most Accumulibacter phosphatis \\
\hline & PAO651 & CCCTCTGCCAAACTCCAG & Most Accumulibacter phosphatis \\
\hline & PAO846 & GTTAGCTACGGCACTAAAAGG & Most Accumulibacter phosphatis \\
\hline & Acc-I- $444^{\mathrm{c}}$ & CCCAAGCAATTTCTTCCCC & Accumulibacter phosphatis clade IA \\
\hline & Acc-II- $444^{\mathrm{c}}$ & CCCGTGCAATTTCTTCCCC & Accumulibacter phosphatis clades IIA, C and D \\
\hline & Actino221 & CGCAGGTCCATCCCAGAC & Tetrasphaera-related Actinobacteria \\
\hline & Actino658 & TCCGGTCTCCCCTACCAT & Tetrasphaera-related Actinobacteria \\
\hline & Bet $135^{\mathrm{d}}$ & ACGTTATCCCCCACTCAATGG & Dechloromonas-related Betaproteobacteria \\
\hline \multirow[t]{8}{*}{ GAO } & GAOQ989 & TTCCCCGGATGTCAAGGC & Some Competibacter phosphatis \\
\hline & GB_G2 & TTCCCCAGATGTCAAGGC & Some Competibacter phosphatis \\
\hline & TFO_DF218 & GAAGCCTTTGCCCCTCAG & Defluviicoccus vanus-related Alphaproteobacteria cluster 1 \\
\hline & TFO_DF618 & GCCTCACTTGTCTAACCG & Defluviicoccus vanus-related Alphaproteobacteria cluster 1 \\
\hline & DF988 & GATACGACGCCCATGTCAAGGG & Defluviicoccus vanus-related Alphaproteobacteria cluster 2 \\
\hline & DF1020 & CCGGCCGAACCGACTCCC & Defluviicoccus vanus-related Alphaproteobacteria cluster 2 \\
\hline & $\operatorname{Bet} 65^{\mathrm{d}}$ & CAGTTGCCCCGCGTACCG & Comamonadaceae-related Betaproteobacteria \\
\hline & $\operatorname{Gam} 455^{\mathrm{d}}$ & CTGACGTATTCGGCCAGTGC & Thioalkalivibrio-related Gammaproteobacteria \\
\hline \multirow[t]{2}{*}{$\mathrm{AOB}$} & NSO1225 & CGCCATTGTATTACGTGTGA & Betaproteobacterial ammonia-oxidizing bacteria \\
\hline & NSO190 & CGATCCCCTGCTTTTCTCC & Betaproteobacterial ammonia-oxidizing bacteria \\
\hline \multirow[t]{2}{*}{ NOB } & NIT3 & CCTGTGCTCCATGCTCCG & Nitrobacter spp. \\
\hline & Ntspa662 & GGAATTCCGCGCTCCTCT & Genus Nitrospira \\
\hline
\end{tabular}

${ }^{\mathrm{a}}$ Oehmen et al. (2006)

${ }^{\mathrm{b}}$ Stahl and Amann (1991)

${ }^{\mathrm{c}}$ Flowers et al. (2009)

${ }^{\mathrm{d}}$ Kong et al. (2007)

(Bet135). The Tetrasphaera-related Actinobacteria were present within the range of $1-8 \%$ in the studied plants (Figs. 1 and 2), except for MBR 2, where they were not detected. This group of PAOs was often the most abundant PAO identified, and in MBR 1 it was the only PAO present. The observed morphology of these cells was similar to that described by Kong et al. (2005), which were mainly short rods dispersed in the biomass, clusters of cocci in the shape of tetrads, and in lower abundance, other clusters of coccobacilli. The Dechloromonas-related PAO targeted by BET135 was detected at levels between $4 \%$ and $9 \%$ in the majority of the MBR plants except for MBRs 1, 5, and 7. Interestingly, this was the dominant PAO in MBR $4(6.1 \%$;
$\mathrm{SE}_{\text {mean }}=0.3 \%$ ), the full-scale EBPR plant, whereas it was not detected in the pilot-scale EBPR plant analyzed in this study (MBR 5). The morphologies of the BET135-targeted organisms included clusters of coccobacilli, as well as large cocci and rods that were more thinly dispersed in the biomass. These morphologies are in agreement with those described by Kong et al. (2007) for this group of putative PAOs. Additional FISH images of the different putative PAO groups can be viewed in Fig. S1.

Overall, the GAOs were present in very low abundance in all the MBRs analyzed in this study (Fig. 1), except for MBR 8. Competibacter was not found in any of the MBRs except for MBR 8, and in this plant it displayed a low 
Table 4 Semiquantification of microbial population by FISH through epifluorescence microscopy

\begin{tabular}{|c|c|c|c|c|c|c|c|c|c|c|c|}
\hline \multirow{2}{*}{$\begin{array}{l}\text { MBR } \\
\text { plant }\end{array}$} & \multirow[b]{2}{*}{ Archaea } & \multicolumn{3}{|c|}{ Proteobacteria group } & \multirow{2}{*}{$\begin{array}{c}\text { HGC } \\
\text { (Actino- } \\
\text { bacteria) }\end{array}$} & \multirow{2}{*}{$\begin{array}{c}\text { Ammonia } \\
\text { oxidizing } \\
\text { bacteria } \\
\text { (AOB) }\end{array}$} & \multirow{2}{*}{$\begin{array}{c}\text { Nitrite } \\
\text { oxidizing } \\
\text { bacteria } \\
\text { (NOB) }\end{array}$} & \multicolumn{3}{|c|}{$\begin{array}{l}\text { Polyphosphate accumulating organisms } \\
\text { (PAO) }\end{array}$} & \multirow{2}{*}{$\begin{array}{c}\text { Glycogen } \\
\text { accumulating } \\
\text { organisms } \\
\text { (GAO) }\end{array}$} \\
\hline & & Alpha & Beta & Gamma & & & & Total PAOs & Acc. Type $\mathrm{I}^{\mathrm{a}}$ & Acc. Type $\|^{a}$ & \\
\hline MBR 1 & $\bullet$ & $\bullet$ & $\bullet \bullet$ & $\bullet$ & $\bullet$ & $\bullet$ & $\bullet$ & $\bullet$ & n.d. & n.d. & • \\
\hline MBR 2 & $\bullet$ & n.d. & $\bullet$ & $\bullet$ & $\bullet$ & $\bullet$ & n.d. & $\bullet$ & $\bullet \bullet$ & $\bullet \bullet \bullet$ & $\bullet$ \\
\hline MBR 3 & - & $\bullet$ & $\bullet \bullet \bullet$ & $\bullet$ & - & $\bullet$ & - & $\bullet \bullet$ & $\bullet \bullet \bullet$ & $\bullet$ & $\bullet$ \\
\hline MBR 4 & - & n.d. & $\bullet \bullet \bullet$ & $\bullet$ & - & $\bullet$ & $\bullet$ & $\bullet$ & $\bullet \bullet$ & $\bullet \bullet$ & $\bullet$ \\
\hline MBR 5 & n.d. & n.d. & $\bullet \bullet$ & $\bullet$ & $\bullet$ & n.d. & n.d. & $\bullet$ & n.d. & n.d. & n.d. \\
\hline MBR 6 & - & $\bullet$ & $\bullet$ & $\bullet$ & - & n.d. & n.d. & $\bullet$ & n.d. & - & $\bullet$ \\
\hline MBR 7 & n.d. & $\bullet$ & $\bullet \bullet$ & $\bullet$ & $\bullet$ & $\bullet$ & $\bullet$ & • & n.d & • & $\bullet$ \\
\hline MBR 8 & - & $\bullet$ & $\bullet \bullet$ & $\bullet$ & $\bullet$ & - & - & $\bullet$ & - & $\bullet \bullet \bullet$ & $\bullet$ \\
\hline
\end{tabular}

${ }^{a}$ semi-quantification in respect to PAOmix; n.d.: not detected ; $\bullet:$ 1-10\%; $\bullet:$ : 10-30\%; $\bullet \bullet: 30-50 \% ; \bullet \bullet \bullet: ~ 50-70 \% \bullet \bullet \bullet \bullet 70-85 \% ; \bullet \bullet \bullet \bullet \bullet 85-100 \%$

relative abundance $\left(2.2 \% ; \mathrm{SE}_{\text {mean }}=0.5 \%\right)$. Similar results were found for the probes targeting Defluviicoccus vanusrelated Alphaproteobacteria: cluster 1 (TFOmix) was not detected and cluster 2 (DEFmix) was only observed in MBRs 3, 6, and 8, where small clusters of cocci were found in very low relative abundance $(\leq 1 \%)$. Bet 65 targeted cells were present in MBRs 3, 4, and 8 at levels ranging between $2 \%$ and $4 \%$. These Comamonadaceae-related Betaproteobacteria were also detected in the other MBRs, except for MBR 5, although they were present in very low abundance $(<1 \%)$. A common morphology identified with Bet65 was short and medium size rods, as previously described (Kong et al. 2007), but clusters of coccobacilli were also observed. Thioalkalivibrio-related Gammaproteobacteria (Gam455) was not detected in any of the studied MBRs.

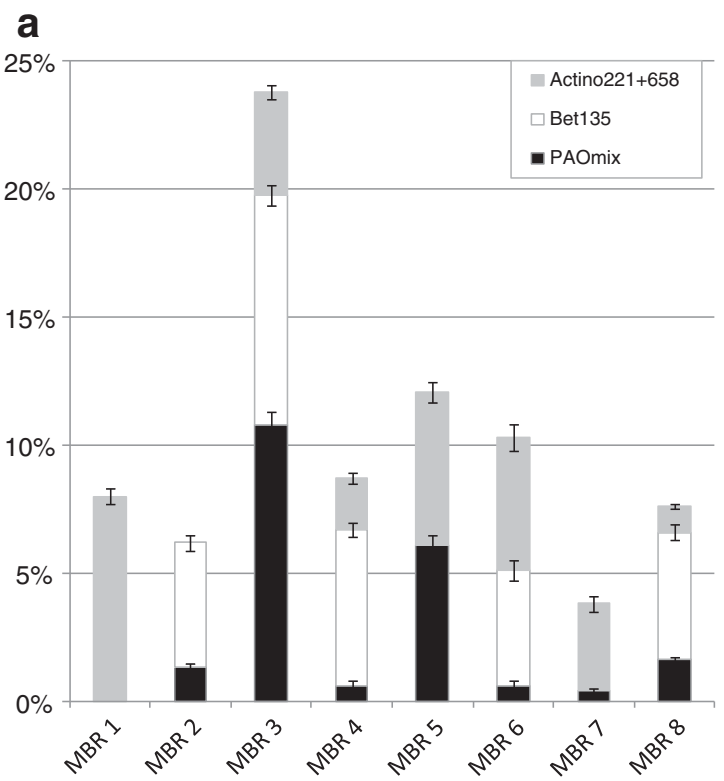

\section{Discussion}

All of the MBRs showed very high ammonia removal efficiencies, except for MBR 6 (Table 2), where no AOBs were detected by FISH analysis. MBR 6 was the only plant in this study with a very low sludge retention time (SRT), which likely justifies the absence of AOBs and NOBs, since these are slow-growing autotrophic organisms that require a longer SRT in order to thrive. In MBR 5, no AOBs were detected, despite the broad coverage of the employed FISH probes, although $\mathrm{NH}_{4}-\mathrm{N}$ was completely removed. Furthermore, no members of the Archaea domain were detected in this plant, suggesting the absence of archaeal ammonia oxidizers (AOA). The high $\mathrm{NH}_{4}-\mathrm{N}$ consumption observed in this plant may have been partially consumed for the growth of heterotrophic biomass (MBR 5

b

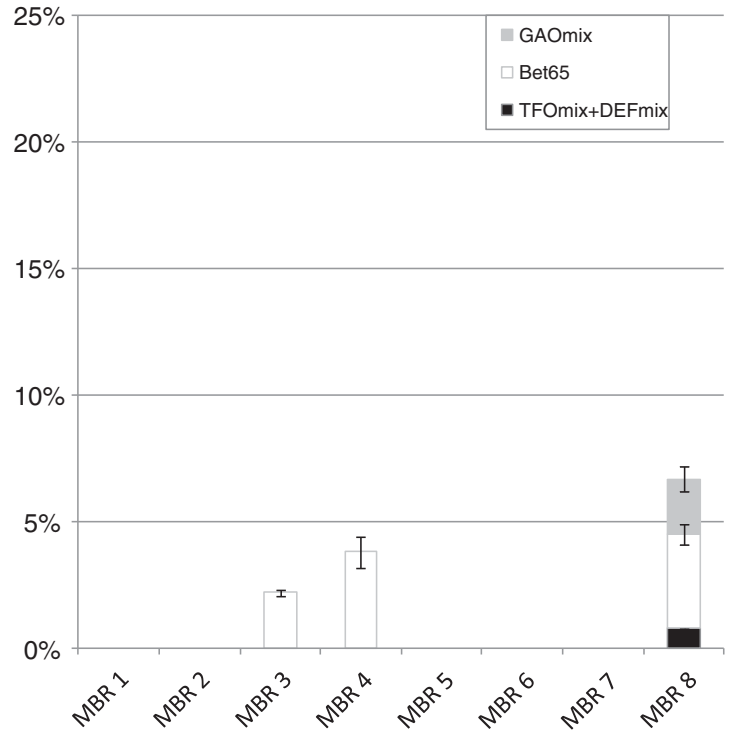

Fig. 1 Quantitative FISH assessment of PAOs (a) and GAOs (b) in the MBR plants studied 
Fig. 2 CLSM micrographs of biomass samples from a MBR 3; b,d MBR 4; and $\mathbf{c}$ MBR 1 hybridized with probes for bacteria (EUBmix, cells in blue) and for Accumulibacter (PAOmix, cells in magenta in $\mathbf{a}$ and $\mathbf{b}$ ) or for Tetrasphaera-related Actinobacteria (Actino 221 and 658 , cells in magenta in $\mathbf{c}$ and d). $\operatorname{Bar}=10 \mu \mathrm{m}$
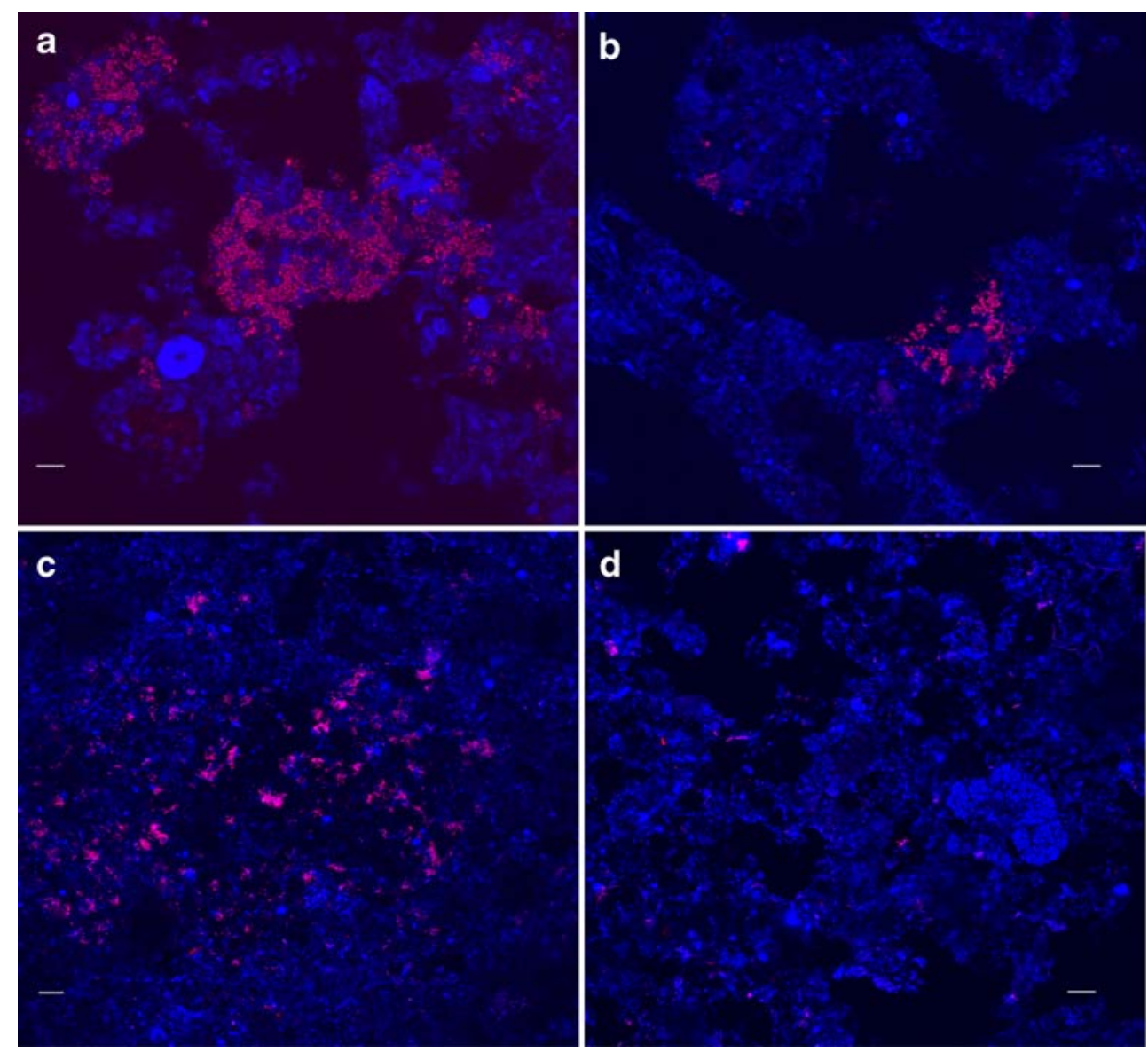

had the highest biomass concentration). Additionally, unidentified AOBs and AOAs that are not covered by the employed FISH probes could be present in this MBR, as has been previously suggested in literature (Witzig et al. 2002; Chen and LaPara 2008).

Comparing the $\mathrm{P}$ removal performance achieved in each plant (Table 2), MBRs 1 to 5 achieved low $\mathrm{P}$ effluent concentrations with a high total level of $\mathrm{P}$ removal, particularly in MBRs 4 and 5, which were designed for EBPR. Between these two EBPR-MBRs, the highest P removal was achieved in MBR 4, where Accumulibacterand Tetrasphaera-PAOs were present in low numbers $(<2 \%$ each), suggesting an active role of the putative Dechloromonas-related PAOs in biological P removal (Fig. 1). MBRs 7 and 8 were both pilot-scale plants and showed poorer P removal as compared to the full-scale MBRs, even those not containing an anaerobic zone. Nevertheless, it should be pointed out that chemical precipitation was applied in MBRs 1 and 2, likely explaining the bulk of the $\mathrm{P}$ removal achieved in these plants. Interestingly, MBR 3 did not contain an anaerobic zone, nor was chemical precipitation applied, but achieved the highest level of $\mathrm{P}$ removal amongst non-EBPR plants. This result is in agreement with the FISH quantification values, which revealed that this plant contained the highest total putative PAO population, surprisingly even substantially higher than the EBPR plants (MBRs 4 and 5). The negligible biological $\mathrm{P}$ removal achieved in MBRs 7 and 8 (not designed for EBPR) correlates well with the fact that the lowest quantity of PAOs was detected in MBR 7 (3.8\%), and the highest quantity of GAOs was detected in MBR $8(6.2 \%)$ (Fig. 1). Moreover, the influent chemical oxygen demand (COD)/P ratio was significantly higher in MBRs 7 and $8(174 \pm 29 \mathrm{mg} \mathrm{COD} /$ $\mathrm{mg} \mathrm{P})$ than the other MBRs $(39 \pm 30 \mathrm{mg} \mathrm{COD} / \mathrm{mg} \mathrm{P}$ ), which also agrees well with the $\mathrm{P}$ removal and microbial population results.

Not only was the total abundance of PAOs highest in a non-EBPR-MBR, but the highest abundance of each individual group of putative PAOs (Accumulibacter, Tetrasphaera-PAOs and Dechloromonas-PAOs) was also observed in non-EBPR-MBRs (Table 5). In general, the $\mathrm{PAO}$ groups were within the range reported in literature, except for the Dechloromonas-PAOs, which presented higher abundances as compared to the EBPR plants studied in Kong et al. (2007), the only reported study to investigate these organisms (Table 5). Nevertheless, most previous studies have investigated the abundance of EBPR-related populations in EBPR plants; very few have presented results concerning the abundance of these 


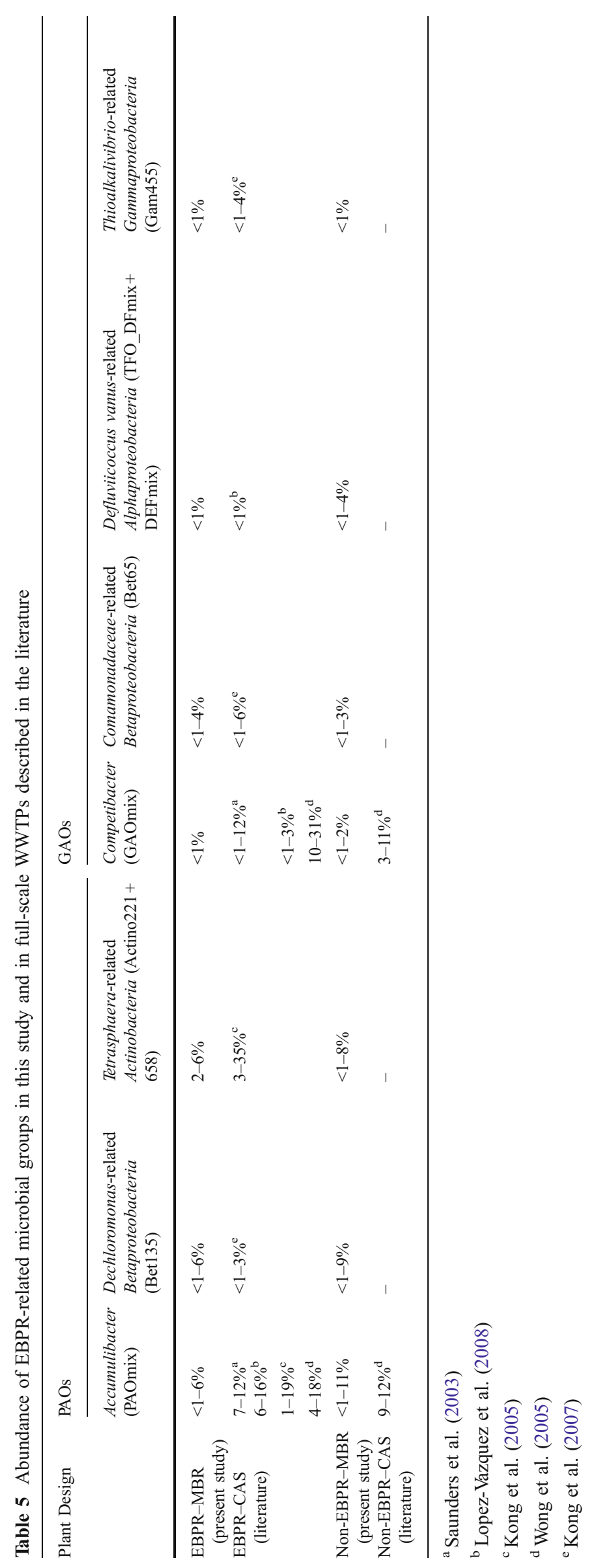


organisms in non-EBPR plants, and no previous studies have investigated PAOs/GAOs in MBRs. Wong et al. (2005) performed the only other study comparing $\mathrm{PAO} /$ GAO abundance in EBPR-CAS vs non-EBPR-CAS plants. In their study, the abundance of Accumulibacter did not vary significantly among the different plants (9$12 \%$ in non-EBPR-CAS and $4-18 \%$ in EBPR-CAS). These results agree very well with our study, where the abundance of not only Accumulibacter, but also the other two putative PAO groups, was within a similar range for EBPR-MBR plants (total putative PAOs, $10 \% \pm 2 \%$ ) and non-EBPR-MBR plants (total putative PAOs, $10 \% \pm 7 \%$ ) (Fig. 1).

These findings suggest that organisms that are considered to be putative PAOs can in fact thrive in systems (MBR or CAS) without anaerobic zones and grow to similar levels as EBPR plants. Their activity as PAOs is dependent on the operational conditions (e.g., presence of alternating anaerobic/aerobic conditions), but not necessarily their total numbers. In fact, putative PAOs can grow under a wide variety of environments (Peterson et al. 2008) and can behave as ordinary heterotrophs (Pijuan et al. 2006). To promote their activity as PAOs, the key is to impose appropriate operational conditions (normally involving an anaerobic zone); however, it is also possible that PAOs take advantage of anaerobic micro-niches occurring in non-EBPR plants. The high MLSS and EPS concentrations typical in MBRs (Judd 2008; Hall et al. 2010) might indeed facilitate the occurrence of these micro-niches, which could justify the good biological P removal observed in MBR 3. In such a situation, it is possible that a higher number of putative PAOs are required to achieve good $\mathrm{P}$ removal performance as compared to a traditional EBPR-designed WWTP. For example, MBRs 4 and 5 were able to remove higher total quantities of $\mathrm{P}$ with lower numbers of putative PAOs (9$12 \%$ ) as compared to MBR $3(24 \%)$, for a similar total biomass concentration. It appears that the putative PAOs detected in MBRs 4 and 5 were behaving as PAOs much more efficiently as compared to MBR 3, a non-EBPRMBR system.

The apparent adaptability and metabolic flexibility of putative PAOs in activated sludge systems with or without a well-defined anaerobic phase is in agreement with the metagenomic analysis of Accumulibacter (Martin et al. 2006). This study showed several metabolic capabilities that could be expressed according to the adaptation required to the surrounding environment, such as the presence of high affinity $\mathrm{P}$ transporters to scavenge $\mathrm{P}$ when present at low concentrations, and a complete set of genes to perform nitrogen fixation, which would enable survival in, e.g., nutrient-limited habitats. Furthermore, MBRs are typically operated with high biomass concentrations, resulting in low food to microorganisms $(\mathrm{F} / \mathrm{M})$ ratios (Table 2), which in turn leads to a limited ATP supply to the biomass (Low and Chase 1999; Witzig et al. 2002; Monclus et al. 2010). Thus, microorganisms capable of alternate means of satisfying their maintenance energy requirements are positively selected in MBRs. In this way, the numbers of PAOs in non-EBPR-MBRs could be explained by both their metabolic flexibility and their ability to accumulate an ATP source (i.e., polyphosphate granules) that can be used to fulfill their energetic requirements in substrate-limited conditions.

Wong et al. (2005) found that in EBPR-CAS plants, Competibacter reached values three times higher than in non-EBPR-CAS. In this study, GAOs were often present in low abundance (Table 5), thus, no trend could be established with respect to the impact of operational conditions typical of MBR technology on GAO selection. It is still unknown if GAOs are as adaptable to nonanaerobic/aerobic environments as PAOs appear to be. The operational conditions that lead to the proliferation of PAOs over GAOs in MBRs, and the promotion of biological phosphorus removal in these systems are topics of interest for future research.

Acknowledgments The authors acknowledge the EUROMBRA project (contract no. 018480 under the Sixth Framework Programme of the European Commission) and their partners for samples and plant data. Fundação para a Ciência e Tecnologia (FCT) is also thankfully acknowledged for the project PTDC/EBB-EBI/098862/2008, and grants SFRH/BD/40969/2007 and SFRH/BPD/30800/2006.

\section{References}

Amann R (1995) In situ identification of microorganisms by whole cell hybridization with rRNA-targeted nucleic acid probes. In: Akkermans ADL, van Elsas JD, de Bruijn FJ (eds) Molecular microbial ecology manual, vol 3.3.6. Kluwer Academic Publications, Dordrecht, pp 1-15

Carvalho G, Lemos PC, Oehmen A, Reis MAM (2007) Denitrifying phosphorus removal: Linking the process performance with the microbial community structure. Water Res 41:4383-4396

Chen RD, LaPara TM (2008) Enrichment of dense nitrifying bacterial communities in membrane-coupled bioreactors. Process Biochem 43:33-41

Flowers JJ, He S, Yilmaz S, Noguera DR, McMahon KD (2009) Denitrification capabilities of two biological phosphorus removal sludges dominated by different "Candidatus Accumulibacter" clades. Environ Microbiol Rep 1(6):583-588

Fu ZM, Yang FL, An YY, Xue Y (2009) Simultaneous nitrification and denitrification coupled with phosphorus removal in an modified anoxic/oxic-membrane bioreactor (A/O-MBR). Biochem Eng J 43:191-196

Hall ER, Monti A, Mohn WW (2010) A comparison of bacterial populations in enhanced biological phosphorus removal processes using membrane filtration or gravity sedimentation for solidsliquid separation. Water Res 44:2703-2714

Judd S (2008) The status of membrane bioreactor technology. Trends Biotechnol 26:109-116 
Kong YH, Nielsen JL, Nielsen PH (2005) Identity and ecophysiology of uncultured actinobacterial polyphosphate-accumulating organisms in full-scale enhanced biological phosphorus removal plants. Appl Environ Microbiol 71:4076-4085

Kong YH, Xia Y, Nielsen JL, Nielsen PH (2007) Structure and function of the microbial community in a full-scale enhanced biological phosphorus removal plant. Microbiology 153:40614073

Kraume M, Bracklow U, Vocks M, Drews A (2005) Nutrients removal in MBRs for municipal wastewater treatment. Water Sci Technol 51:391-402

Le-Clech P (2010) Membrane bioreactors and their uses in wastewater treatments. Appl Microbiol Biotechnol 88:1253-1260

Lesjean B, Gnirss R, Buisson H, Keller S, Tazi-Pain A, Luck F (2005) Outcomes of a 2-year investigation on enhanced biological nutrients removal and trace organics elimination in membrane bioreactor (MBR). Water Sci Technol 52:453460

Li H, Yang M, Zhang Y, Liu X, Gao M, Kamagata Y (2005) Comparison of nitrification performance and microbial community between submerged membrane bioreactor and conventional activated sludge system. Water Sci Technol 51:193-200

Lopez-Vazquez CM, Hooijmans CM, Brdjanovic D, Gijzen HJ, van Loosdrecht MCM (2008) Factors affecting the microbial populations at full-scale enhanced biological phosphorus removal (EBPR) wastewater treatment plants in the Netherlands. Water Res 42:2349-2360

Low EW, Chase HA (1999) The effect of maintenance energy requirements on biomass production during wastewater treatment. Water Res 33:847-853

Luxmy BS, Nakajima F, Yamamoto K (2000) Analysis of bacterial community in membrane-separation bioreactors by fluorescent in situ hybridization (FISH) and denaturing gradient gel electrophoresis (DGGE) techniques. Water Sci Technol 41:259-268

Manser R, Gujer W, Siegrist H (2005) Membrane bioreactor versus conventional activated sludge system: population dynamics of nitrifiers. Water Sci Technol 52:417-425

Martin HG, Ivanova N, Kunin V, Warnecke F, Barry KW, McHardy AC, Yeates C, He SM, Salamov AA, Szeto E, Dalin E, Putnam NH, Shapiro HJ, Pangilinan JL, Rigoutsos I, Kyrpides NC, Blackall LL, McMahon KD, Hugenholtz P (2006) Metagenomic analysis of two enhanced biological phosphorus removal (EBPR) sludge communities. Nat Biotechnol 24:1263-1269

Monclus H, Sipma J, Ferrero G, Rodriguez-Roda I, Comas J (2010) Biological nutrient removal in an MBR treating municipal wastewater with special focus on biological phosphorus removal. Bioresour Technol 101:3984-3991

Nielsen PH, Daims H, Lemmer H (2009) FISH handbook for biological wastewater treatment. IWA Publishing, London

Oehmen A, Zeng RJ, Saunders AM, Blackall LL, Keller J, Yuan ZG (2006) Anaerobic and aerobic metabolism of glycogen- accumulating organisms selected with propionate as the sole carbon source. Microbiology 152:2767-2778

Oehmen A, Lemos PC, Carvalho G, Yuan ZG, Keller J, Blackall LL, Reis MAM (2007) Advances in enhanced biological phosphorus removal: from micro to macro scale. Water Res 41:2271-2300

Pala I, Kolukirik M, Insel G, Ince O, Cakar ZP, Orhon D (2008) Fluorescence in situ hybridization for the assessment of nitrifying bacteria in a pilot-scale membrane bioreactor. Fresenius Environ Bull 17:2255-2261

Parco V, du Toit G, Wentzel M, Ekama G (2007) Biological nutrient removal in membrane bioreactors: denitrification and phosphorus removal kinetics. Water Sci Technol 56:125-134

Peterson SB, Warnecke F, Madejska J, McMahon KD, Hugenholtz P (2008) Environmental distribution and population biology of Candidatus Accumulibacter, a primary agent of biological phosphorus removal. Environ Microbiol 10:2692-2703

Pijuan M, Guisasola A, Baeza JA, Carrera J, Casas C, Lafuente J (2006) Net P-removal deterioration in enriched PAO sludge subjected to permanent aerobic conditions. J Biotechnol 123:117-126

Saunders AM, Oehmen A, Blackall LL, Yuan Z, Keller J (2003) The effect of GAOs (glycogen accumulating organisms) on anaerobic carbon requirements in full-scale Australian EBPR (enhanced biological phosphorus removal) plants. Water Sci Technol 47:37-43

Seviour RJ, McIlroy S (2008) The microbiology of phosphorus removal in activated sludge processes - the current state of play. $\mathrm{J}$ Microbiol 46:115-124

Smolders GJF, van der Meij J, van Loosdrecht MCM, Heijnen JJ (1994) Stoichiometric model of the aerobic metabolism of the biological phosphorus removal process. Biotechnol Bioeng 44:837-848

Sofia A, Liu WT, Ong SL, Ng WJ (2004) In situ characterization of microbial community in an $\mathrm{A} / \mathrm{O}$ submerged membrane bioreactor with nitrogen removal. Water Sci Technol 50:41-48

Stahl DA, Amann R (1991) Development and application of nucleic acid probes. In: Stackebrandt E, Goodfellow M (eds) Nucleic acid techniques in bacterial systematics. Wiley, Chichester, pp 205-248

Wagner M, Loy A (2002) Bacterial community composition and function in sewage treatment systems. Curr Opin Biotechnol 13:218-227

Wan C-Y, De Wever H, Diels L, Thoeye C, Liang J-B, Huang L-N (2011) Biodiversity and population dynamics of microorganisms in a full-scale membrane bioreactor for municipal wastewater treatment. Water Res 45:1129-1138

Witzig R, Manz W, Rosenberger S, Kruger U, Kraume M, Szewzyk U (2002) Microbiological aspects of a bioreactor with submerged membranes for aerobic treatment of municipal wastewater. Water Res 36:394-402

Wong MT, Mino T, Seviour RJ, Onuki M, Liu WT (2005) In situ identification and characterization of the microbial community structure of full-scale enhanced biological phosphorous removal plants in Japan. Water Res 39:2901-2914 